\title{
DISCUSSION
}

\section{Importance of Tightly Coupled Equations in Model- ling Grassland Ecological Economics}

A response to "Modelling the Economics of Grassland Degradation in Banni, India, using System Dynamics" (Mihir Mathur and Kabir Sharma, EES, July 2018)

\section{Chandanathil P. Geevan, ${ }^{*}$ Arun M. Dixit ${ }^{* *}$ and Chandra S. Silori ${ }^{* * *}$}

The research reported by Mathur and Sharma (2018), referred hereafter as $\mathrm{M} \& S$, analyses the interactions between ecology and economy of the Banni grassland, located in the district of Kachchh, Gujarat, through a system dynamic model factoring in area covered by the invasive mesquite Prosopis juliflora (mesquite-covered area, hereafter MCA, $\mathrm{A}_{p}$ in M\&S) and the incomes from livestock and mesquite. M\&S has, however, overlooked the previous work on economy-ecology linkages of the region (Geevan et al 2003, 2005). Certain selections from the Geevan et al study, the discussion on system dynamics modelling framework, were published by INSEE as a book chapter (Sengupta and Bandyopadhyay 2005). While M\&S has cited Geevan et al (2003) several times, its system dynamics model, which is central to the work, was overlooked. This oversight seems to have led to several flawed formulations in M\&S. We briefly point out these.

Our study (Geevan et al 2003) had adapted certain concepts of grassland resource dynamics modelling from the work of Perrings ${ }^{1}$ (Perrings 1994,

* Centre for Environment and Social Concerns, C-612 Siddi Vinayak Towers, Behind DCP Office Off. S.G.Highway, Makarba, Ahmedabad 380051, India; cpgeevan@cesc-india.org $₫$

** Centre for Environment and Social Concerns, C-612 Siddi Vinayak Towers, Behind DCP Office Off. S.G.Highway, Makarba, Ahmedabad, 380051, India; arunmdixit@gmail.com

*** RECOFTC - The Center for People and Forests, P.O. Box 1111, Kasetsart Post Office, Bangkok 10903, Thailand; chandra.silori@recoftc.org

Copyright (C) Geevan, Dixit and Silori 2019. Released under Creative Commons AttributionNonCommercial 4.0 International licence (CC BY-NC 4.0) by the author.

Published by Indian Society for Ecological Economics (INSEE), c/o Institute of Economic Growth, University Enclave, North Campus, Delhi 110007.

ISSN: 2581-6152 (print); 2581-6101 (web).

DOI: https://doi.org/10.37773/ees.v2i1.59 
1997; Perrings and Walker 1995; Perrings and Stern 2000). Perrings integrated an ecological model of rangeland resource dynamics into an economic analysis framework. It is important to recognize that the challenge in such studies is to model the variables as a tightly interdependent system; the separate uncoupled equations fail to provide insights into the interesting features

The system dynamic model presented in our work is very briefly described here for quick reference. It incorporates three state variables $\mathrm{X}, \mathrm{K}$, and $\mathrm{W}$, where $\mathrm{X}$ is the livestock numbers expressed in Adult Cattle Units ${ }^{2}$ (ACU), $\mathrm{K}$ is grazing potential per ha of the grassland, and $\mathrm{W}$ woody area invaded by mesquite. The terms, $\mathrm{Q}_{1}, \mathrm{Q}_{2}, \mathrm{Q}_{3}$ and $\mathrm{Q}_{4}$ represent control variables -offtake with negative values representing infusion. $\mathrm{Q}_{1}$ is the off-take of livestock in ACU, $\mathrm{Q}_{2}$ is the grazing potential removed for milk production, $\mathrm{Q}_{3}$ is the woody cover from which charcoal is produced resulting in a temporary reduction of the woody cover through coppicing and $\mathrm{Q}_{4}$ is the area from which woody cover is reduced by uprooting every year. Additionally, there is a discrete parameter $\theta$ or switch representing the control of the mesquite re-invasion which takes the value 0 or $1 ; 0$ with reinvasion and 1 without re-invasion (i.e. with adequate measures). It is important to note that a) biomass harvest without uprooting the mesquite (e.g., coppicing to make wood charcoal) does not significantly slow down the spatial spread and b) mesquite will reinvade areas from which it has been completely removed in the absence of measures to stop the spread.

In contrast to the coupled equations employed by us to concurrently compute livestock number, grazing potential and MCA (X, K, and W), M\&S use a standalone approach separately for the MCA and the livestock sector. For the former, they employed a single variable equation without any explicit dependency on the livestock sector. They invoke the dependency on livestock by employing a 'graphical function' for E, a livestock dependent multiplier of the rate of spatial spread.

The following comments pertain to certain specifics of the model presented by M\&S:

1. M\&S use a parameter called 'normal spread rate' (n), the annual increment in MCA. It has been assigned a value of $8.5 \%$ per year, which is a very large value for 'normal' (i.e., unassisted) spread. MCA will nearly double in about eight years with such a large compound annual

\footnotetext{
${ }^{1}$ Discussed with Charles Perrings during the Sixth INSEE Biennial Conference and later through correspondence.

${ }^{2}$ Expressing livestock numbers in Adult Cattle Units (ACU) is a standard practice to account for livestock across different types.
} 
growth rate in the absence of any controlling factors. Note that in the formulation of M\&S, parameter ' $n$ ' is also multiplied by another parameter $\mathrm{E}(1 \leq \mathrm{E} \leq 2)$, which means the effective rate of spatial spread in the model ranges from $8.5 \%$ to $17 \%$ per year, which is much higher than the observed spatial spread. The rate of spatial spread in the absence of animal vectors or any other additional dispersal mechanism will be much lower. In our work, we assigned a nominal value several orders of magnitude less for the parameter representing the natural rate of spatial spread $\left(\alpha_{3}\right)$ based on inferences drawn from our own analysis of the satellite imagery data of different periods and literature.

2. M\&S cite the work of Vaibhav et al. (2012), the preliminary results presented at a conference, as the source for the value of 'normal spread rate' referred to earlier. Curiously, this study is not on the spatial spread of mesquite, but on biomass regeneration under coppicing. Vaibhav et al (2012) uses single satellite imagery of 2011 - a period when the Banni region was invaded by mesquite and livestock presence was high. The estimated rate of spatial spread of mesquite in Banni reported in a recent study was 2.1\% per year (Pasha et al 2014), arrived at after examining satellite imagery datasets of 1977, 1990, 1999, 2005 and 2011. Since livestock vectors are present in large numbers in this landscape, the value is the livestock-mediated rate, i.e., the enhanced value, not the 'normal' or 'natural' rate. There are no historical records of any period for the Banni region without large numbers of livestock. Consequently, there are no known studies providing estimates of the natural rate of spread in the region in the absence of livestock.

3. M\&S use a graphical representation of $\mathrm{E}$, the multiplier of the 'normal' rate (n). In our work, we had characterized the multiplier effect on the natural rate, $\alpha_{3}(1+\varepsilon \mathrm{X})$ with $\varepsilon$ as the parameter representing the enhanced rate of spatial spread of woody cover per thousand ACU due to the presence of livestock $(\mathrm{X})$ expressed in terms of ACU. The device of a simple graphical lookup function, akin to a function lookup table, employed by $M \& S$ is inadequate to simulate a tightly interconnected system as it cannot concurrently generate the values of the livestock sector.

4. Further, in our view, there is a major error in the way M\&S have formulated the equation for the change in MCA by making the rate of change proportional to the current area. Our work considered this as a rather non-intuitive aspect (Geevan et al 2003, 2005). It is tempting to assume that the change in area will be proportional to the current area as is usually done, e.g., the future population as proportional to the current value. However, the primary driver of an increase in the mesquite area is the livestock transporting seeds from the periphery of the mesquite- 
covered patches. They do not graze inside the thick woody growth. Therefore, in our work, we expressed the increase in mesquite-cover as proportional to the square root of the area (i.e., a proxy for the length of the periphery) as a more realistic formulation representing the spatial spread of mesquite. We recognize there are challenges in characterizing this process as realistically as possible.

5. There are also several deficiencies in the second standalone model of livestock dynamics, which we shall not discuss in detail. It will suffice to state that the equations for the dynamics of the stock of adults, B and calves, $\mathrm{C}$, maturing into adults at age $\mathrm{T}_{\mathrm{m}}$, do not seem to adequately represent the dynamics in a consistent manner.

The aim of this comment is to draw attention to the nuances of developing a system dynamics model of economic activity dependent on an open access resource subject to mesquite invasion.

\section{REFERENCES}

Geevan, C.P., A.M. Dixit, and C.S. Silori. 2003. "Ecological Economic Analysis of Grassland Systems.” EERC Working Paper Series: CPR-5.

Geevan, C.P., A.M. Dixit, and C.S. Silori. 2005. "Dynamics of the Resource Economics of Open Access Grasslands - Kachchh District (Gujarat).” In Biodiversity and Quality of Life edited by N. Sengupta, and J. Bandyopadhyay, 236-252. New Delhi: Macmillan.

Mathur, M. and K. Sharma. 2018. "Modelling the Economics of Grassland Degradation in Banni, India, using System Dynamics." Ecology, Economy and Society - the INSEE Journal 1 (2): 31- 65. DOI: https://doi.org/10.37773/ees.v1i2.34

Pasha, S.V., K.V. Satish, C.S. Reddy, P.P. Rao, and C.S. Jha. 2014. "Satellite image-based quantification of invasion and patch dynamics of mesquite (Prosopis juliflora) in Great Rann of Kachch, Kachchh Biosphere Reserve, Gujarat, India." Journal of Earth System Science 123 (7): 1481-1490. https://doi.org/10.1007/s12040-014-0486-0

Perrings, C. 1994. "Stress, Shock and Sustainability of Resource Use in Semi-Arid Environments." The Annals of Regional Science 28: 3-53. https://doi.org/10.1007/BF01581347 Perrings, C. 1997. Economics of Ecological Resources: Selected Essays. Cheltenham: Edward Elgar. Perrings, C. and D.I. Stern. 2000. "Modelling Loss in Agroecosystems: Rangelands in Botswana." Environmental and Resource Economics 16: 185-210. https://doi.org/10.1023/A:1008374222463

Perrings, C. and B.W. Walker. 1995. "Biodiversity loss and economics of discontinuous change in semiarid rangelands." In Biodiversity Loss - Economic and Ecological Issues edited by C. Perrings, K. Maler, C. Folke, C.S. Holling, and B. Jansson, 90-210. Cambridge: Cambridge University Press. https://doi.org/10.1017/CBO9781139174329.009

Sengupta, N. and J. Bandyopadhyay, eds. 2005. Biodiversity and Quality of Life. New Delhi: Macmillan.

Vaibhav, V., A.B. Inamdar, and D.N. Bajaj. 2012. "Above ground biomass and carbon stock estimation from P. juliflora in Banni grassland using satellite and ancillary data". 33rd Asian Conference on Remote Sensing, November 26-30, 2012, Thailand. 